\title{
National trends in utilization and in-hospital outcomes of mechanical versus bioprosthetic aortic valve replacements
}

\author{
Abby J. Isaacs, MS, ${ }^{a}$ Jeffrey Shuhaiber, MD, ${ }^{b}$ Arash Salemi, MD, ${ }^{c}$ O. Wayne Isom, MD, ${ }^{c}$ and \\ Art Sedrakyan, $\mathrm{MD}, \mathrm{PhD}^{\mathrm{a}}$
}

\section{ABSTRACT}

Objective: Substantial controversy surrounds the choice between a mechanical versus bioprosthetic prosthesis for aortic valve replacement (AVR), based on age. This study aims to investigate national trends and in-hospital outcomes of the 2 prosthesis choices.

Methods: All patients aged $>18$ years in the National Inpatient Sample who received an AVR between 1998 and 2011 were considered. Valve-type use was examined by patient, procedural, and hospital characteristics, after which we matched patients based on their propensity score for receiving a bioprosthetic valve and compared their in-hospital outcomes.

Results: Bioprosthetic valves comprised 53.3\% of 767,375 implanted valves, an increase in use from $37.7 \%$ in the period 1998 to 2001 to $63.6 \%$ in the period 2007 to 2011. The median age was 74 years for patients receiving bioprosthetic valves, and 67 years for those receiving mechanical valves. Use of bioprosthetic valves increased across all age groups, most markedly in patients age 55 to 64 years. Compared with patients receiving mechanical valves, these patients had a higher incidence of renal disease $(8.0 \%$ vs $4.2 \%)$, coronary artery disease $(58.5 \%$ vs $50.5 \%)$, concomitant coronary artery bypass grafting ( $46.7 \%$ vs $41.9 \%)$, and having surgery in a highvolume ( $>250$ cases per year) center $(31.3 \%$ vs $18.5 \%)$. Patients receiving bioprosthetic valves had a higher occurrence of in-hospital complications $(55.9 \%$ vs $48.6 \%)$, but lower in-hospital mortality ( $4.4 \%$ vs $4.9 \%)$ than patients receiving mechanical valves. This difference was confirmed in propensity-matched analyses (complications: $52.7 \%$ vs $51.5 \%$; mortality: $4.3 \%$ vs $5.2 \%$ ).

Conclusions: Use of bioprosthetic valves in AVR increased dramatically from 1998 to 2011, particularly in patients age 55 to 64 years. Prosthesis selection varied significantly by facility, with low-volume facilities favoring mechanical valves. Aortic valve replacement with a bioprosthetic valve, compared with a mechanical valve, was associated with lower in-hospital mortality. (J Thorac Cardiovasc Surg 2015;149:1262-9)

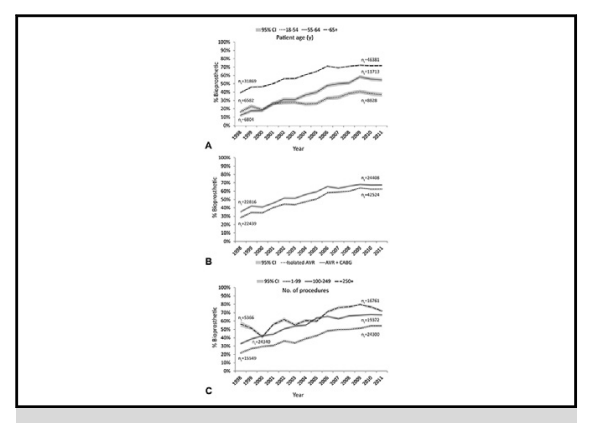

Percent bioprosthetic aortic valves $1998-2011$ by (A) age, (B) concomitant $\mathrm{CABG}$, and $(\mathrm{C})$ hospital valve volume.

\section{Central Message}

We found that bioprosthetic aortic valve use is increasing nationally, particularly in patients age 55 to 64 years. Use varies by center, with low-volume facilities using more mechanical valves. Bioprosthetic valves are associated with lower in-hospital mortality, compared with mechanical valves.

\section{Perspective}

Substantial uncertainty remains regarding the choice of mechanical versus bioprosthetic devices for aortic valve replacement. We found substantial variation, nationally, among centers, in type of valves used, ranging from $0 \%$ to $100 \%$ bioprosthetic or mechanical. Our finding that lower in-hospital mortality is associated with bioprosthetic valves is novel and requires reflection by the surgical community. More-frequent use of mechanical valves, and the related higher mortality in low-volume hospitals, might require a review and policy intervention to ensure appropriate patient and valve selection.

See Editorial page 1242.
From the Department of Healthcare Policy and Research, ${ }^{\mathrm{a}}$ Weill Cornell Medical College, New York, NY; Department of Cardiothoracic Surgery, ${ }^{\mathrm{b}}$ Rhode Island Hospital and Hasbro Children's Hospital, Brown Medical School, Providence, RI; and Department of Cardiothoracic Surgery, ${ }^{\mathrm{c}}$ New York Presbyterian HospitalWeill Cornell Medical College, New York, NY.

Art Sedrakyan received funding from the U.S. Food and Drug Administration for establishing the MDepiNet Science and Infrastructure Center (grants \#U01FD004494 and \#U01FD004939). Abby Isaacs is a senior analyst at the center.

Received for publication Nov 11, 2014; revisions received Jan 12, 2015; accepted for publication Jan 24, 2015; available ahead of print March 17, 2015

Address for reprints: Art Sedrakyan, MD, PhD, Weill Cornell Medical College, $402 \mathrm{E}$ 67th St, Suite 223, New York, NY 10065 (E-mail: ars2013@med.cornell.edu).

$0022-5223 / \$ 36.00$

Copyright (c) 2015 by The American Association for Thoracic Surgery

http://dx.doi.org/10.1016/j.jtcvs.2015.01.052
丹 Supplemental material is available online.

Aortic valve replacement (AVR) is the recommended treatment for severe aortic stenosis, including high-risk patients who can tolerate surgery. ${ }^{1}$ Substantial controversy remains regarding the criteria that should guide the choice of the type of implanted valves. Since the inception of heart valve surgery, mechanical or bioprosthetic valves have been the mainstream options. ${ }^{2}$ Clinical trials with long-term follow-up and meta-analyses have shown that overall survival for the 2 valve types-mechanical and 


\section{Abbreviations and Acronyms \\ AVR = aortic valve replacement \\ $\mathrm{CABG}=$ coronary artery bypass grafting \\ HCUP $=$ Healthcare Cost and Utilization Project \\ NIS = National Inpatient Sample}

bioprosthetic - is approximately equivalent. However, mechanical valves require ongoing anticoagulation, leading to potential bleeding complications; bioprosthetic valves are more prone to deteriorate over time and require reintervention. ${ }^{3-6}$ The American College of Cardiology working with the American Heart Association and the European Society of Cardiology working with the European Association of Cardio-Thoracic Surgery released reports recommending that the patient, cardiologists, and surgeons collectively decide on a valve type after considering factors such as life expectancy and risks of chronic anticoagulation, or accelerated valve deterioration. ${ }^{7,8}$

The design of bioprosthetic valves has evolved over time, with stented bioprosthetic valves becoming more popular in recent years, making them attractive for most patients ${ }^{9-11}$; however, some valves, such as pericardial valves, show lower midterm survival in patients who are age $<60$ years. ${ }^{12}$ Additional analyses have encouraged greater use of bioprosthetic valves in the elderly ${ }^{13}$ (specifically those age $>65$ years, per American College of Cardiology and American Heart Association guidelines). Schelbert and colleagues $^{14}$ observed that high-volume hospitals were more likely to use bioprosthetic valves in the elderly, during the period 1999 to 2001 . Brown and colleagues ${ }^{15}$ found that adoption of biologic valves increased between 1998 and 2006; during the same time period, in-hospital death and stroke after valve replacement decreased. Similar trends have been observed in Great Britain and Ireland. ${ }^{16}$ With changing opinions over time on what constitutes appropriate valve choice, examination of trends and outcomes of current practice in bioprosthetic and mechanical valve use is critical, in not only the elderly, but also younger age groups.

Most current decision-making criteria are based on differences in long-term outcomes discovered in randomized clinical trials. ${ }^{3-5}$ Although such studies are an essential tool for comparing treatments, they lack the large sample sizes needed to investigate differences in rarer outcomes, ${ }^{17}$ such as complications and mortality. A national-level study of 1994 data found valve prosthesis type to be a significant predictor of in-hospital mortality in AVR, including surgeries where more than one valve was replaced $^{18}$; a recent study in the elderly found greater shortterm mortality with mechanical, versus bioprosthetic, valves. ${ }^{19}$ The effect in both studies disappeared when only isolated AVR was examined, without concurrent coronary artery bypass grafting (CABG). In the current study, we evaluated differences in use of bioprosthetic versus mechanical valves, and in-hospital outcomes, in a nationally representative cohort including all ages and all payers.

\section{METHODS \\ Data Source}

The National (formerly Nationwide) Inpatient Sample (NIS) is maintained by the Agency for Healthcare Research and Quality, as part of the Healthcare Cost and Utilization Project (HCUP). The NIS is the largest all-payer inpatient-care database in the United States and constitutes approximately a $20 \%$ stratified sample of all hospital discharges from nongovernment institutions. Data contained within the NIS include patient and hospital demographics, admission and treating diagnoses, inpatient procedures, length of hospital stay, hospital charges, and discharge status. The stratified sample design and the discharge-level weighting allow the calculation of national estimates of healthcare utilization. ${ }^{20}$ This study was found to be exempt by the Institutional Review Board of Weill Cornell Medical College (Protocol No. 1209013064) and conforms to the data-use agreement for the NIS from HCUP.

\section{Study Cohort}

All patients aged $>18$ years who received a bioprosthetic or mechanical (ICD9 CM [International Classification of Diseases, Clinical Modification] codes 35.21 and 35.22, respectively) AVR at an HCUP NIS-participating hospital from 1998 to 2011 were considered. Patients who underwent a simultaneous valve annuloplasty, valve repair, or mitral or tricuspid valve replacement were excluded.

\section{Variables}

We categorized patients according to age, in years (18-54, 55-64, 65-74, $\geq 75$ ), gender (female, male), race (white, nonwhite), year of procedure, and insurance status (Medicare, Medicaid, commercial, or other). We identified patients with diagnoses of coronary artery disease, heart failure, hypertension, diabetes, chronic pulmonary disease, peripheral vascular disease, and chronic renal insufficiency, according to the indexed hospitalization, using validated algorithms. ${ }^{21}$ In addition, we used hospital-level information available in the NIS data to categorize treatment centers according to: location with respect to US Census regions (North, West, Midwest, South); size (small, medium, large); ownership (private, investor-owned; private, nonprofit; government, nonfederal); teaching hospital status; and location (urban, rural). Given that the NIS data contain all procedures that were done in a given hospital, but do not necessarily include the same hospitals in any given year's sample, we used the hospital's unique identifier to calculate an average annual volume for valve repair and replacement procedures per facility; we additionally examine these data by group, according to procedure volume (1-99, 100-249, $\geq 250$ procedures).

\section{Outcomes}

The study outcomes were in-hospital mortality, in-hospital complications, and a composite outcome of in-hospital mortality and stroke. To investigate complications of surgery in the NIS cohort, for cases in which diagnosis dates during the hospitalization are not available, we considered only postoperative complications or those listed as complications using appropriate codes. We identified patients with the following complications: cardiovascular (postoperative stroke, cardiac tamponade, cardiac arrest or insufficiency, cardiorespiratory failure, heart failure during or resulting from surgery); pulmonary (pneumonia, postoperative pulmonary insufficiency, postoperative acute pneumothorax, postoperative edema, collapsed lung, empyema, mechanical ventilation for $>72$ hours); infections (sepsis and/or shock, urinary tract, postoperative wound); bleeding 
(intracranial hemorrhage, gastrointestinal, bleeding that complicates a procedure); and thromboembolic. Additionally, we considered discharge status as either routine or nonroutine (death; to another level of care; against medical advice).

\section{Statistical Analysis}

Baseline characteristics for the study population are reported and compared using percentages and $\chi^{2}$ analysis for categoric variables; and medians, interquartile ranges, and Wilcoxon rank-sum tests for continuous variables. Procedure utilization is examined over time, graphically, by patient age, concomitant CABG, and hospital volume. The use data presented are weighted to reflect national estimates.

We created a propensity score for each patient's probability of receiving a bioprosthetic valve, using logistic regression for potential confounding variables of year of surgery, age group, gender, coronary artery disease, congestive heart failure, hypertension, diabetes, chronic pulmonary disease, renal disease, concurrent $\mathrm{CABG}$, hospital teaching status, and hospital valve-procedure volume. Patients were paired based on the logit of the propensity score, using a 1:1 nearest-neighbor-matching algorithm, ${ }^{22}$ with a minimum difference of 0.2 times the standard deviation, as recommended by Austin. ${ }^{23}$ We assessed balance using the postmatch c-statistic and standardized differences (Table E1). ${ }^{24}$

After matching, we ran a sensitivity analysis to see if results were consistent in isolated, first-time aortic-valve recipients who did not have endocarditis. In addition, we tested sensitivity to alternate model specifications and to facility-level variation, by matching patients within centers. In the propensity-matched cohort, all statistical comparisons are made using tests for paired data. All analyses were performed using SAS, version 9.3 (SAS Institute, Inc, Cary, NC).

\section{RESULTS}

Bioprosthetic valves made up most $(53.3 \%)$ of an estimated 767,375 implanted valves. In the years 1998 to 2001 , only $37.7 \%$ of the valves were bioprosthetic, but this proportion increased to $63.6 \%$ in the years 2007 to 2011 (Figure 1). Patients aged $<65$ years were more likely to receive mechanical valves, whereas patients aged $\geq 75$ years were more likely to receive bioprosthetic valves. This finding is consistent with the higher proportions of patients who received bioprosthetic, versus mechanical, valves being Medicare recipients $(73.0 \%$ vs $53.6 \%)$. Patients who received bioprosthetic, versus mechanical, valves were more likely to have coronary artery disease $(58.5 \%$ vs $50.5 \%)$, and to require concomitant CABG $(46.7 \%$ vs $41.9 \%)$. In addition, they were more likely, compared with those who received mechanical valves, to have congestive heart failure ( $35.7 \%$ vs $32.7 \%$ ), hypertension $(52.2 \%$ vs $48.7 \%$ ), diabetes $(23.7 \%$ vs $21.0 \%)$, chronic pulmonary disease $(19.5 \%$ vs $18.2 \%)$, and chronic renal insufficiency $(8.0 \%$ vs $4.2 \%)$. Mechanical valve recipients were more likely, compared with those who received bioprosthetic valves, to have peripheral vascular disease $(18.6 \%$ vs $17.5 \%)$. As the propensity-matched cohort has been balanced for these differences, the matched patients receiving bioprosthetic valves are generally younger and have fewer comorbidities than the national population (Table 1).

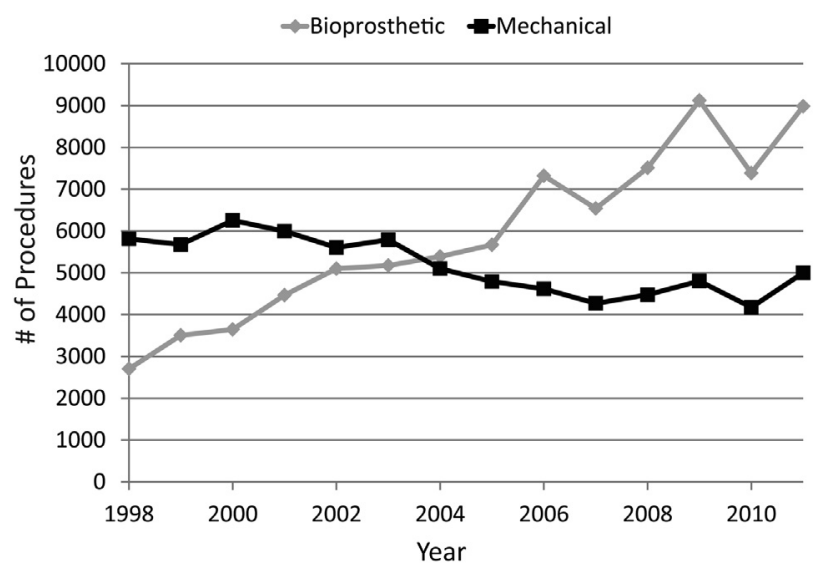

FIGURE 1. Estimated national volume of bioprosthetic and mechanical aortic valve replacement procedures, by year, from 1998 to 2011.

Patients receiving bioprosthetic valves were more likely to have surgery in a high-volume ( $>250$ cases per year) center $(31.3 \%)$, compared with patients receiving mechanical valves (18.5\%); in fact, $44.7 \%$ of cases involving mechanical valves were in centers with $<100$ valve-replacement procedures per year (Table 1). The percentage of use of valve types at the hospital level showed significant variation (Figure 2). Although the highest percentage of bioprosthetic valves are used in patients age $>65$ years, use has been increasing across age groups, most markedly in those age 55 to 64 years. The slightly higher level of use of bioprosthetic valves in patients undergoing concomitant CABG has remained unchanged over time. Although low-volume hospitals doubled their use level of bioprosthetic valves from 1998 to 2011, it is consistently lower than that of midand high-volume facilities (Figure 3).

In unadjusted, weighted national data, being in the group of patients who received bioprosthetic valves, versus in the group who received mechanical valves, was associated with, respectively: a longer length of stay (in days; median 8 , interquartile range: $6-13$ vs median 6 , interquartile range: $8-12, P<.001)$; a higher occurrence of in-hospital complications $(55.9 \%$ vs $48.6 \%, P<.001)$; and more nonroutine discharges $(61.4 \%$ vs $47.1 \%, P<.001)$, but lower in-hospital mortality $(4.4 \%$ vs $4.9 \%, P<.001)$. In the propensity-matched cohort, in which known patient and hospital risk factors have been balanced between the 2 valve groups, higher in-hospital mortality was found among patients who received mechanical valves $(5.2 \%)$, compared with bioprosthetic valves $(4.4 \%) ; P<.001$. Post-valve surgery complications were still slightly higher with bioprosthetic, versus mechanical, valves $(53.0 \%$ vs $51.1 \%, P<.001)$. In addition, discharges to nursing homes and skilled nursing facilities were higher in the group receiving bioprosthetic valves $(56.2 \%$ vs $51.7 \%)$. Within the subset of patients who had a complication, in-hospital mortality was lower with bioprosthetic, versus mechanical, 
TABLE 1. Comparisons of demographics, patient comorbidities, and hospital characteristics, for AVR with mechanical, versus bioprosthetic, valves from 1998 to 2011

\begin{tabular}{|c|c|c|c|c|}
\hline \multirow[b]{2}{*}{ Characteristic } & \multicolumn{2}{|c|}{ Weighted national estimates } & \multicolumn{2}{|c|}{ Propensity-matched cohort } \\
\hline & $\begin{array}{c}\text { Bioprosthetic } \\
\text { AVR }(n=409,003)\end{array}$ & $\begin{array}{c}\text { Mechanical } \\
\operatorname{AVR}(\mathbf{n}=\mathbf{3 5 8 , 3 7 2})\end{array}$ & $\begin{array}{c}\text { Bioprosthetic } \\
\operatorname{AVR}(n=\mathbf{4 8 , 4 2 3})\end{array}$ & $\begin{array}{c}\text { Mechanical } \\
\operatorname{AVR}(n=48,423)\end{array}$ \\
\hline \multicolumn{5}{|l|}{ Procedure } \\
\hline CABG & $191,135(46.7)$ & $150,089(41.9)$ & $21,941(45.3)$ & $22,026(45.5)$ \\
\hline Elective* & $263,397(65.8)$ & $225,034(65.1)$ & $31,624(65.3)$ & $31,674(65.4)$ \\
\hline \multicolumn{5}{|l|}{ Patient } \\
\hline Median age (y [IQR]) & $74(66-80)$ & $67(56-76)$ & $71(62-78)$ & $71(62-78)$ \\
\hline \multicolumn{5}{|l|}{ Age (y) } \\
\hline $18-54$ & $33,712(8.2)$ & $79,189(22.1)$ & $6207(12.8)$ & $6343(13.1)$ \\
\hline $55-64$ & $51,886(12.7)$ & $76,661(21.4)$ & 8524 (17.6) & $8416(17.4)$ \\
\hline $65-74$ & $127,654(31.2)$ & $98,765(27.6)$ & $15,413(31.8)$ & $15,439(31.9)$ \\
\hline$\geq 75$ & $195,750(47.9)$ & $103,757(29.0)$ & $18,279(37.7)$ & $18,225(37.6)$ \\
\hline \multicolumn{5}{|l|}{ Gender* } \\
\hline Female & $154,290(37.7)$ & $128,578(35.9)$ & $18,021(37.2)$ & $17,969(37.1)$ \\
\hline Male & $254,681(62.3)$ & $229,742(64.1)$ & $30,402(62.8)$ & $30,454(62.9)$ \\
\hline \multicolumn{5}{|l|}{ Race $\dagger$} \\
\hline White & $284,679(87.3)$ & $226,777(83.1)$ & $31,833(85.2)$ & $31,935(85.4)$ \\
\hline Nonwhite & $41,492(12.7)$ & 46,199 (16.9) & $5525(14.8)$ & $5480(14.6)$ \\
\hline \multicolumn{5}{|l|}{ Year of procedure } \\
\hline $1998-2001$ & $72,859(17.8)$ & $120,217(33.5)$ & $11,179(23.1)$ & $10,993(22.7)$ \\
\hline $2002-2006$ & $140,239(34.3)$ & $125,944(35.1)$ & $18,493(38.2)$ & $18,639(38.5)$ \\
\hline $2007-2011$ & $195,905(47.9)$ & $112,211(31.3)$ & $18,751(38.7)$ & $18,791(38.8)$ \\
\hline \multicolumn{5}{|l|}{ Diagnosis } \\
\hline Endocarditis & $10,049(2.5)$ & $9981(2.8)$ & $1339(2.8)$ & $1342(2.8)$ \\
\hline Rheumatic valve disease & $52,952(12.9)$ & $39,432(11.0)$ & $5660(11.7)$ & $5767(11.9)$ \\
\hline Congenital aortic valve disease & $32,238(7.9)$ & $30,849(8.6)$ & $4034(8.3)$ & $4047(8.4)$ \\
\hline Thoracic aortic aneurysm & $26,635(6.5)$ & $31,011(8.7)$ & $3637(7.5)$ & $3598(7.4)$ \\
\hline \multicolumn{5}{|l|}{ Comorbidities } \\
\hline Chronic anticoagulation & $12,857(3.1)$ & $12,047(3.4)$ & $1543(3.2)$ & $1536(3.2)$ \\
\hline Coronary artery disease & $239,067(58.5)$ & $180,850(50.5)$ & $26,653(55.0)$ & $26,706(55.2)$ \\
\hline Congestive heart failure & $146,079(35.7)$ & $117,139(32.7)$ & $16,435(33.9)$ & $16,384(33.8)$ \\
\hline Hypertension & $213,628(52.2)$ & $174,685(48.7)$ & $24,587(50.8)$ & $24,579(50.8)$ \\
\hline Diabetes & $96,797(23.7)$ & $75,406(21.0)$ & $11,012(22.7)$ & $11,020(22.8)$ \\
\hline Chronic pulmonary disease & $79,874(19.5)$ & $65,207(18.2)$ & $9390(19.4)$ & $9265(19.1)$ \\
\hline Peripheral vascular disease & $71,469(17.5)$ & $66,746(18.6)$ & 8989 (18.6) & $8941(18.5)$ \\
\hline Chronic renal insufficiency and/or failure & $32,565(8.0)$ & $15,021(4.2)$ & $2746(5.7)$ & $2728(5.6)$ \\
\hline \multicolumn{5}{|l|}{ Insurance* } \\
\hline Medicare & $298,305(73.0)$ & $191,580(53.6)$ & $31,277(64.6)$ & $31,324(64.7)$ \\
\hline Medicaid & $10,153(2.5)$ & $16,164(4.5)$ & $1640(3.4)$ & $1676(3.5)$ \\
\hline Commercial & $89,523(21.9)$ & $131,780(36.8)$ & $13,812(28.5)$ & $13,783(28.5)$ \\
\hline Other (uninsured) & $10,478(2.6)$ & $18,196(5.1)$ & $1694(3.5)$ & $1640(3.4)$ \\
\hline \multicolumn{5}{|l|}{ Hospital } \\
\hline Median annual valve-procedure volume (IQR) & $197(109-342)$ & $137(73-247)$ & $129(68-229)$ & $133(74-230)$ \\
\hline \multicolumn{5}{|l|}{ Annual valve- volume (no. of procedures) } \\
\hline $1-99$ & $116,031(28.4)$ & $160,113(44.7)$ & $18,365(37.9)$ & $18,452(38.1)$ \\
\hline $100-249$ & $165,131(40.4)$ & $131,999(36.8)$ & $19,263(39.8)$ & $19,170(39.6)$ \\
\hline$\geq 250$ & $127,841(31.3)$ & $66,260(18.5)$ & $10,795(22.3)$ & $10,801(22.3)$ \\
\hline \multicolumn{5}{|l|}{ Size (no. of beds)* } \\
\hline Small & $22,733(5.6)$ & $20,016(5.6)$ & $3006(6.2)$ & $2896(6.0)$ \\
\hline Medium & $69,146(16.9)$ & $64,996(18.2)$ & 9053 (18.7) & $8285(17.1)$ \\
\hline Large & $316,135(77.5)$ & $271,904(76.2)$ & $36,364(75.1)$ & $37,242(76.9)$ \\
\hline
\end{tabular}


TABLE 1. Continued

\begin{tabular}{|c|c|c|c|c|}
\hline \multirow[b]{2}{*}{ Characteristic } & \multicolumn{2}{|c|}{ Weighted national estimates } & \multicolumn{2}{|c|}{ Propensity-matched cohort } \\
\hline & $\begin{array}{c}\text { Bioprosthetic } \\
\text { AVR }(n=409,003)\end{array}$ & $\begin{array}{c}\text { Mechanical } \\
\operatorname{AVR}(n=358,372)\end{array}$ & $\begin{array}{c}\text { Bioprosthetic } \\
\operatorname{AVR}(\mathrm{n}=\mathbf{4 8 , 4 2 3})\end{array}$ & $\begin{array}{c}\text { Mechanical } \\
\text { AVR }(n=48,423)\end{array}$ \\
\hline \multicolumn{5}{|l|}{ Ownership* } \\
\hline Private, investor owned & $34,649(8.6)$ & $33,543(9.5)$ & $4703(9.8)$ & $4509(9.4)$ \\
\hline Private, nonprofit & $347,060(85.7)$ & $285,340(81.2)$ & $39,917(83.1)$ & $39,043(81.5)$ \\
\hline Government, nonfederal & $23,030(5.7)$ & $32,519(9.3)$ & $3396(7.1)$ & $4364(9.1)$ \\
\hline \multicolumn{5}{|l|}{ Setting* } \\
\hline Teaching hospital & $281,038(68.9)$ & $234,834(65.8)$ & $31,943(66.0)$ & $31,831(65.7)$ \\
\hline Urban & 396,577 (97.2) & $344,811(96.6)$ & $46,798(96.6)$ & $46,783(96.6)$ \\
\hline \multicolumn{5}{|l|}{ Region } \\
\hline Midwest & $90,320(22.1)$ & $91,084(25.4)$ & $11,512(23.8)$ & $11,374(23.5)$ \\
\hline Northeast & $117,625(28.8)$ & $70,832(19.8)$ & $10,659(22.0)$ & $10,796(22.3)$ \\
\hline South & $118,551(29.0)$ & $127,090(35.5)$ & $17,129(35.4)$ & $17,124(35.4)$ \\
\hline West & $82,508(20.2)$ & $69,367(19.4)$ & $9123(18.8)$ & $9129(18.9)$ \\
\hline
\end{tabular}

Values are $\mathrm{n}(\%)$, unless otherwise indicated. All measures for comorbidities, except coronary artery disease and anticoagulation history, were created from definitions in the Elixhauser Comorbidity Index, using HCUP Comorbidity Software, version 3.7 (Agency for Healthcare Research and Quality, Rockville, Md). AVR, Aortic valve replacement; $C A B G$, coronary artery bypass grafting; $I Q R$, interquartile range. $*<3 \%$ missing. $\dagger \sim 22 \%$ missing.

valves, in both the national sample $(6.3 \%$ vs $7.6 \%$, $P<.001)$ and the propensity-matched cohort $(6.4 \%$ vs $7.8 \%, P<.001$ ) (Table 2).

In a subgroup of isolated, patients who underwent AVR and did not have endocarditis, we saw lower mortality with bioprosthetic, versus mechanical, valves in both the national $(3.4 \%$ vs $3.7 \%, P=.067)$ and propensitymatched cohorts $(3.3 \%$ vs $3.9 \%, P<.001)$. No statistically significant differences were found in complications between the 2 groups (Table E2). Further, the results were not found to be sensitive to facility-level variation (Table E3).

\section{DISCUSSION}

Our study shows that in-hospital mortality is substantially lower in patients receiving bioprosthetic valves, versus mechanical valves. This difference persisted after risk adjustment via propensity-score matching for surgery

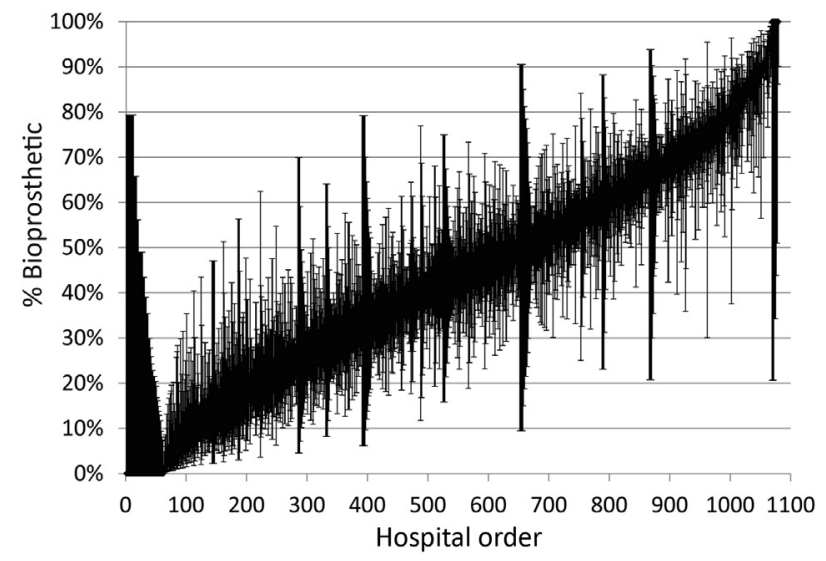

FIGURE 2. Percentage of aortic valve replacements in which bioprosthetic valves were implanted, by hospital. year, patient characteristics, hospital characteristics, and the subset of isolated, first-time valve replacement patients who did not have endocarditis. Mechanical valves necessitate complex, postoperative, anticoagulation management, and debate remains over what determines optimal treatment protocols. ${ }^{25,26}$ In a systematic review of early postoperative anticoagulation after mechanical valve replacement, Kulik and colleagues $^{25}$ report that thromboembolism and anticoagulant-related bleeding account for $75 \%$ of all complications after mechanical valve replacement, often occurring in the first 6 months after surgery, including serious complications such as cardiac tamponade and gastrointestinal bleeding. In a mixed cohort of patients who had anticoagulation issues, including those with valve replacement as an indication, Oden and Fahlén ${ }^{27}$ found an association between a high international normalized ratio and higher all-cause mortality.

Our study provides additional evidence related to short-term bioprosthetic and mechanical implant outcomes, in all age groups, that is consistent with recent observational evidence. For example, Du and colleagues ${ }^{19}$ examined 66,453 Medicare beneficiaries aged $>65$ years who underwent AVR between 2006 and 2011 and found that the risk of death on the date of surgery was $60 \%$ higher for mechanical-valve recipients, compared with bioprosthetic-valve recipients. This difference may be a recent development; an analysis ${ }^{16}$ of 41,227 patients receiving AVR (29,611 with bioprosthetic valves), who are listed in the Society for Cardiothoracic Surgery in Great Britain and the Ireland National Database, showed that in-hospital mortality in recipients of biologic valves has decreased significantly, from $5.1 \%$ in 2004 to $4.0 \%$ in $2009(P=.008)$. Although the Veteran's Affairs and Edinburgh Heart Valve randomized controlled trials, which 


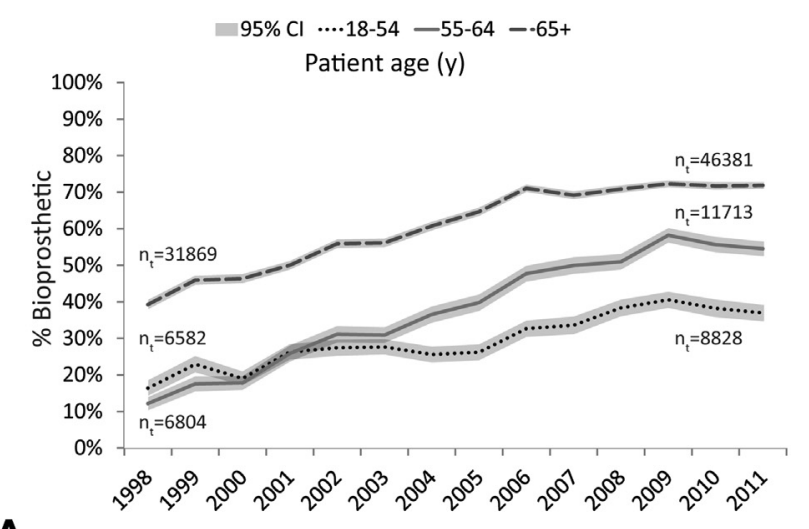

A
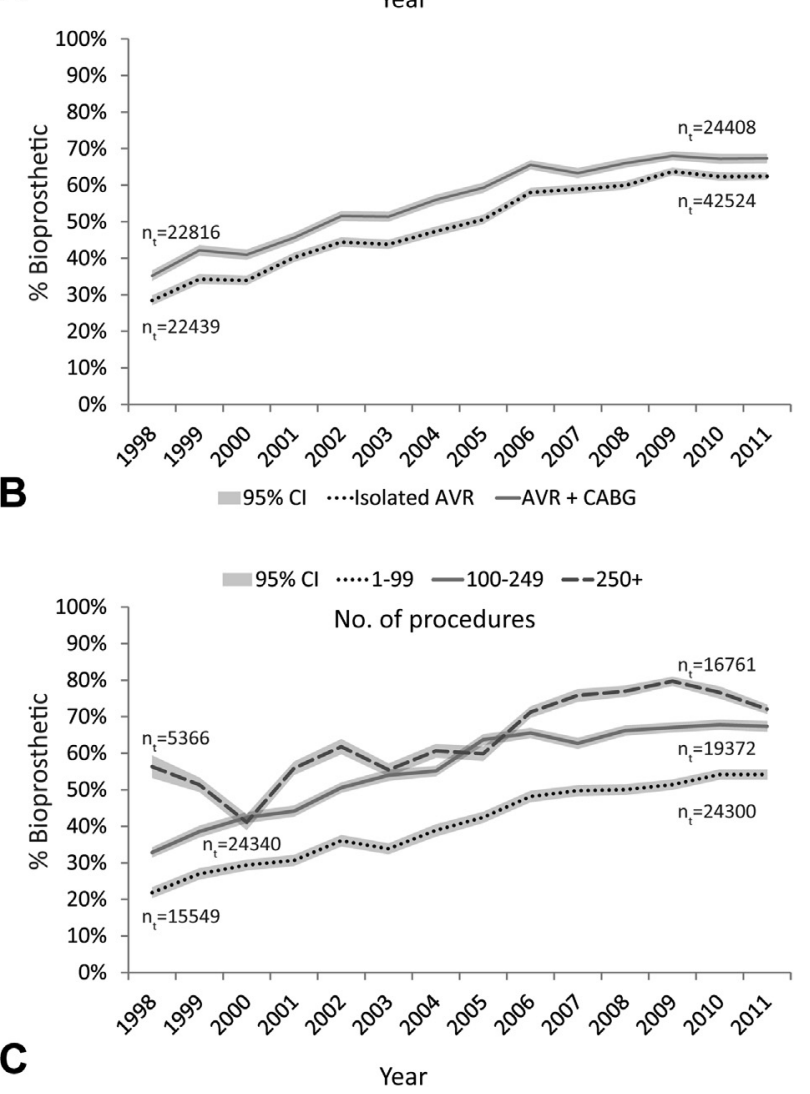

FIGURE 3. Percentage of aortic valve replacements in which bioprosthetic valves were implanted, over time, by (A) patient age; (B) concomitant $\mathrm{CABG}$; and (C) hospital valve-procedure volume. $C I$, Confidence interval; $N_{t}$, total number of aortic valve replacements in each group in 1998 and 2011; $A V R$, aortic valve replacement; $C A B G$, coronary artery bypass grafting.

recruited and performed implantations for patients between 1975 and 1979, did not detect a difference in short-term mortality based on prosthesis type $\mathrm{e}^{3,28}$ the trials often are not reflective of modern or national practice in the United States.

Although our study found significant mortality differences based on valve type, complications were roughly equivalent between the 2 groups, with the exception of more bleeding and overall complications in the group receiving bioprosthetic valves. This phenomenon is not uncommon. In a study comparing the top $20 \%$ of hospitals to the lowest $20 \%$ of hospitals with respect to risk-adjusted mortality in Medicare patients, Ghaferi and colleagues ${ }^{29}$ found that mortality from complications varied greatly, whereas complication rates differed very little. For patients undergoing AVR, specifically, complication rates were $33.5 \%$ in hospitals where risk-adjusted mortality was high, versus $27.1 \%$ for hospitals where it was low; in addition, they found that mortality in patients with complications in hospitals where this risk was high was $26.0 \%$, compared with $7.3 \%$ for hospitals where this risk was low. Reddy and colleagues ${ }^{30}$ examined 45,904 patients at 33 Michigan centers and found that "failure to rescue" was an important factor and was related to high and low observed-to-expected mortality rates. In fact, "death rate among surgical inpatients with serious treatable complications" has been included in the Agency for Healthcare Research and Quality's patient safety hospital quality metrics. ${ }^{31}$

We have demonstrated that valve-prosthesis selection varies significantly at the hospital-level. Further, we found that low-volume institutions consistently use fewer bioprosthetic valves than do mid- and high-volume institutions, supporting earlier findings. ${ }^{14}$ Gonzalez and colleagues ${ }^{32}$ found that hospital volume was more strongly associated with failure to rescue patients who developed major complications than with the development of major complications. In low-volume hospitals, patients who had complications were $57 \%$ more likely to die than were patients who had complications in high-volume facilities. Thus, hospital volume is an important confounder and might provide a partial explanation for differences in mortality between the groups receiving bioprosthetic versus mechanical valves. However, the mortality differences persisted when facility-level variation was removed.

We observed that valve choice is heavily influenced by age, with most patients aged $>75$ years receiving bioprosthetic valves, and younger patients (ages 18-64 years) receiving mechanical valves. In addition, we see that use of bioprosthetic valves is increasing most rapidly among those age 55 to 64 years. This increase is likely partially a result of recent recommendations that are based on evidence that mechanical and bioprosthetic valves are acceptable for those age 60 to 65 years. $^{7}$ Although our data in younger age groups should be reassuring, they still require reflection by stakeholders.

In theory, age may additionally play a greater role in bioprosthetic-valve selection for patients with, versus without, comorbidities, specifically in coronary artery disease patients requiring revascularization. One study ${ }^{33}$ investigating the age threshold for bioprosthetic-valve use found that bioprosthetic valves are appropriate for use in 
TABLE 2. In-hospital outcomes for recipients of mechanical, versus bioprosthetic, valves, from 1998 - to 2011

\begin{tabular}{|c|c|c|c|c|c|c|c|c|}
\hline \multirow[b]{2}{*}{ Outcome } & \multicolumn{4}{|c|}{ Weighted national estimates } & \multicolumn{4}{|c|}{ Propensity-matched cohort } \\
\hline & $\begin{array}{c}\text { Bioprosthetic } \\
\text { AVR } \\
(n=409,003)\end{array}$ & $\begin{array}{c}\text { Mechanical } \\
\text { AVR } \\
(\mathbf{n}=\mathbf{3 5 8 , 3 7 2})\end{array}$ & $\begin{array}{l}\text { Odds ratio } \\
(95 \% \mathrm{CI})\end{array}$ & $\begin{array}{c}P \\
\text { value }\end{array}$ & $\begin{array}{c}\text { Bioprosthetic } \\
\text { AVR } \\
(n=48,423)\end{array}$ & $\begin{array}{c}\text { Mechanical } \\
\text { AVR } \\
(n=\mathbf{4 8 , 4 2 3})\end{array}$ & $\begin{array}{l}\text { Odds ratio } \\
(95 \% \mathrm{CI})\end{array}$ & $\begin{array}{c}P \\
\text { value }\end{array}$ \\
\hline In-hospital mortality* & $17,864(4.4)$ & $17,429(4.9)$ & $1.12(1.07-1.17)$ & $<.001$ & $2095(4.3)$ & $2533(5.2)$ & $1.22(1.15-1.29)$ & $<.001$ \\
\hline $\begin{array}{l}\text { Composite outcome } \\
\text { (death or stroke) }\end{array}$ & $25,360(6.2)$ & $22,783(6.4)$ & $1.03(0.99-1.07)$ & .206 & $2897(6.0)$ & $3330(6.9)$ & $1.16(1.1-1.22)$ & $<.001$ \\
\hline $\begin{array}{l}\text { Length of stay } \\
\qquad(\mathrm{d} ; \text { median }[\mathrm{IQR}])\end{array}$ & $6(8-13)$ & $8(6-12)$ & $\mathrm{n} / \mathrm{a}$ & $<.001$ & $8(6-12)$ & $8(6-13)$ & $\mathrm{n} / \mathrm{a}$ & $<.001$ \\
\hline \multicolumn{9}{|c|}{ Morbidity (type of complication) } \\
\hline Any & $228,632(55.9)$ & $174,014(48.6)$ & $0.74(0.73-0.76)$ & $<.001$ & $25,531(52.7)$ & $24,956(51.5)$ & $0.95(0.93-0.98)$ & $<.001$ \\
\hline Cardiovascular. & $79,351(19.4)$ & $56,917(15.9)$ & $0.78(0.76-0.81)$ & $<.001$ & $8734(18.0)$ & $8140(16.8)$ & $0.92(0.89-0.95)$ & $<.001$ \\
\hline Pulmonary & $104,313(25.5)$ & $79,277(22.1)$ & $0.83(0.81-0.85)$ & $<.001$ & $11,469(23.7)$ & $11,572(23.9)$ & $1.01(0.98-1.04)$ & .437 \\
\hline Infection & $34,124(8.3)$ & $22,396(6.2)$ & $0.73(0.7-0.76)$ & $<.001$ & $3489(7.2)$ & $3624(7.5)$ & $1.04(0.99-1.09)$ & .096 \\
\hline Bleeding & $106,054(25.9)$ & $77,151(21.5)$ & $0.78(0.77-0.8)$ & $<.001$ & $11,470(23.7)$ & $11,060(22.8)$ & $0.95(0.93-0.98)$ & .002 \\
\hline Thromboembolic & 7728 (1.9) & $5329(1.5)$ & $0.78(0.72-0.85)$ & $<.001$ & $831(1.7)$ & 814 (1.7) & $0.98(0.89-1.08)$ & .672 \\
\hline $\begin{array}{l}\text { Mortality in patients } \\
\text { with any } \\
\text { complication }\end{array}$ & $14,489 / 228,632(6.3)$ & $13,170 / 174,014$ (7.6) & $1.21(1.15-1.28)$ & $<.001$ & $1638 / 25,531(6.4)$ & $1957 / 24,956(7.8)$ & $1.29(1.17-1.41)$ & $<.001$ \\
\hline \multicolumn{9}{|l|}{ Discharge status* } \\
\hline Routine & $139,881(34.3)$ & $171,832(48.0)$ & $1.78(1.74-1.81)$ & $<.001$ & $19,322(40.0)$ & $20,430(42.3)$ & $1.11(1.08-1.14)$ & $<.001$ \\
\hline
\end{tabular}

younger patients regardless of concomitant CABG. We do see much higher levels of use of bioprosthetic valves for patients with renal disease, which is encouraging, as studies have shown that patients with mechanical valves who are on anticoagulation medications have a high risk of bleeding and stroke. ${ }^{34}$

To our knowledge, this study represents the largest, all-age-group-based, national-level study of in-hospital trends and outcomes of mechanical and bioprosthetic valve implantations. Further, we show hospital surgical practice trends across the United States.

\section{Limitations}

We recognize that our analysis has limitations. The most important one is that this study is observational and therefore has inherent selection biases, which can be controlled for, but never completely eliminated. We attempted to account for this bias by using propensityscore matching; however, we can balance the sample based on only known patient and hospital characteristics. The NIS is based on mandatory discharge data (claims) but does not contain patient variables that likely influence treatment selection and outcomes, including structural characteristics of the valve, patient-prosthesis mismatch, patient anticoagulation and/or antiplatelet therapy, and implant details, such as the manufacturer, whether the implant is stented, and whether it is bovine or porcine. Conditions that are not tied to billing may be underreported. We did not consider atrial fibrillation, which could be categorized as both a comorbidity and a complication of surgery, as the database does not differentiate between these. The severity of specific complications cannot be assessed within NIS data. Further, the NIS does not contain any data on patients postdischarge, but this information is beyond our scope at this time.

\section{CONCLUSIONS}

Bioprosthetic valves are associated with lower in-hospital mortality, compared with mechanical prostheses, which come at the cost of slightly higher rates of in-hospital complications. Use of bioprosthetic valves for AVR has increased by $>70 \%$ during the past 14 years, particularly for patients age 55 to 64 years. Older patients with coronary artery disease and renal failure are more likely to receive bioprosthetic than mechanical valves. The type of valve used varies significantly by facility, with low-volume and nonteaching facilities using mechanical valves more often. Additional clinical studies to better understand the protective effect of bioprosthetic valves are needed.

\section{Conflict of Interest Statement}

Art Sedrakyan received funding from the US FDA for establishing the MDEpiNet Science and Infrastructure Center. Abby J. Isaacs is a senior analyst at the center. Arash Salemi reports consulting fees from Edwards Lifesciences. All other authors have nothing to disclose with regard to commercial support.

\section{References}

1. Carabello BA, Paulus WJ. Aortic stenosis. Lancet. 2009;373:956-66.

2. Suri RM, Schaff HV. Selection of aortic valve prostheses: contemporary reappraisal of mechanical versus biologic valve substitutes. Circulation. 2013; 128:1372-80.

3. Hammermeister K, Sethi GK, Henderson WG, Grover FL, Oprian C, Rahimtoola SH. Outcomes 15 years after valve replacement with a mechanical versus a bioprosthetic valve: final report of the Veterans Affairs randomized trial. J Am Coll Cardiol. 2000;36:1152-8. 
4. Oxenham H, Bloomfield P, Wheatley DJ, Lee RJ, Cunningham J, Prescott RJ, et al. Twenty year comparison of a Bjork-Shiley mechanical heart valve with porcine bioprostheses. Heart. 2003;89:715-21.

5. Stassano P, Di Tommaso L, Monaco M, Iorio F, Pepino P, Spampinato N, et al. Aortic valve replacement: a prospective randomized evaluation of mechanical versus biological valves in patients ages 55 to 70 years. J Am Coll Cardiol. 2009;54:1862-8.

6. Lund O, Bland M. Risk-corrected impact of mechanical versus bioprosthetic valves on long-term mortality after aortic valve replacement. J Thorac Cardiovasc Surg. 2006;132:20-6.e3.

7. Vahanian A, Alfieri O, Andreotti F, Antunes MJ, Barón-Esquivias G, Baumgartner $\mathrm{H}$, et al. Guidelines on the management of valvular heart disease (version 2012): The Joint Task Force on the Management of Valvular Heart Disease of the European Society of Cardiology (ESC) and the European Association for Cardio-Thoracic Surgery (EACTS). Eur Heart J. 2012;33:2451-96.

8. Nishimura RA, Otto CM, Bonow RO, Carabello BA, Erwin JP, Guyton RA, et al. 2014 AHA/ACC guideline for the management of patients with valvular heart disease: a report of the American College of Cardiology/American Heart Association Task Force on Practice Guidelines. J Am Coll Cardiol. 2014;63:e57-185.

9. Vesely I. The evolution of bioprosthetic heart valve design and its impact on durability. Cardiovasc Pathol. 2003;12:277-86.

10. Christ T, Grubitzsch H, Claus B, Konertz W. Long-term follow-up after aortic valve replacement with Edwards Prima Plus stentless bioprostheses in patients younger than 60 years of age. J Thorac Cardiovasc Surg. 2014;147:264-9.

11. McClure RS, McGurk S, Cevasco M, Maloney A, Gosev I, Wiegerinck EM, et al. Late outcomes comparison of nonelderly patients with stented bioprosthetic and mechanical valves in the aortic position: a propensity-matched analysis. $J$ Thorac Cardiovasc Surg. 2014;148:1931-9.

12. Weber A, Noureddine H, Englberger L, Dick F, Gahl B, Aymard T, et al. Ten-year comparison of pericardial tissue valves versus mechanical prostheses for aortic valve replacement in patients younger than 60 years of age. J Thorac Cardiovasc Surg. 2012;144:1075-83.

13. Birkmeyer NJ, Birkmeyer JD, Tosteson AN, Grunkemeier GL, Marrin CA, O'Connor GT. Prosthetic valve type for patients undergoing aortic valve replacement: a decision analysis. Ann Thorac Surg. 2000;70:1946-52.

14. Schelbert EB, Vaughan-Sarrazin MS, Welke KF, Rosenthal GE. Hospital volume and selection of valve type in older patients undergoing aortic valve replacement surgery in the United States. Circulation. 2005;111:2178-82.

15. Brown JM, O’Brien SM, Wu C, Sikora JAH, Griffith BP, Gammie JS. Isolated aortic valve replacement in North America comprising 108,687 patients in 10 years: changes in risks, valve types, and outcomes in the Society of Thoracic Surgeons National Database. J Thorac Cardiovasc Surg. 2009;137:82-90.

16. Dunning J, Gao H, Chambers J, Moat N, Murphy G, Pagano D, et al. Aortic valve surgery: marked increases in volume and significant decreases in mechanical valve use-an analysis of 41,227 patients over 5 years from the Society for Cardiothoracic Surgery in Great Britain and Ireland National database. J Thorac Cardiovasc Surg. 2011;142:776-82.e3.

17. Cook JA, McCulloch P, Blazeby JM, Beard DJ, Marinac-Dabic D, Sedrakyan A, et al. IDEAL framework for surgical innovation 3: randomised controlled trials in the assessment stage and evaluations in the long term study stage. BMJ. 2013; 346:f2820.

18. Astor BC, Kaczmarek RG, Hefflin B, Daley WR. Mortality after aortic valve replacement: results from a nationally representative database. Ann Thorac Surg. 2000;70:1939-45.
19. Du D, McKean S, Kelman JA, Laschinger J, Johnson C, Warnock R, et al. Early mortality after aortic valve replacement with mechanical prosthetic vs bioprosthetic valves among Medicare beneficiaries: a population-based cohort study. JAMA Intern Med. 2014;174:1788-95.

20. Introduction to the HCUP Nationwide Inpatient Sample (NIS). 2011. Available at: http://www.hcup-us.ahrq.gov/db/nation/nis/NIS_Introduction_2011.jsp. Accessed September 24, 2014

21. Elixhauser A, Steiner C, Harris DR, Coffey RM. Comorbidity measures for use with administrative data. Med Care. 1998;36:8-27.

22. Rassen J, Doherty M, Huang W, Schneeweiss S. Pharmacoepidemiology toolbox. Available at: http://www.drugepi.org/dope-downloads/. Accessed May 13, 2014

23. Austin PC. Propensity-score matching in the cardiovascular surgery literature from 2004 to 2006: a systematic review and suggestions for improvement J Thorac Cardiovasc Surg. 2007; 134:1128-35.e3

24. Yang D, Dalton J. A unified approach to measuring the effect size between two groups using SAS. SAS Global Forum, 2012. Available at: http://support. sas.com/resources/papers/proceedings12/335-2012.pdf. Accessed December 17, 2014.

25. Kulik A, Rubens FD, Wells PS, Kearon C, Mesana TG, van Berkom J, et al. Early postoperative anticoagulation after mechanical valve replacement: a systematic review. Ann Thorac Surg. 2006;81:770-81.

26. Sundt TM, Zehr KJ, Dearani JA, Daly RC, Mullany CJ, McGregor CGA, et al. Is early anticoagulation with warfarin necessary after bioprosthetic aortic valve replacement? J Thorac Cardiovasc Surg. 2005;129:1024-31.

27. Odén A, Fahlén M. Oral anticoagulation and risk of death: a medical record linkage study. BMJ. 2002;325:1073-5.

28. Bloomfield P, Kitchin AH, Wheatley DJ, Walbaum PR, Lutz W, Miller HC. A prospective evaluation of the Björk-Shiley, Hancock, and Carpentier-Edwards heart valve prostheses. Circulation. 1986;73:1213-22.

29. Ghaferi AA, Birkmeyer JD, Dimick JB. Complications, failure to rescue, and mortality with major inpatient surgery in Medicare patients. Ann Surg. 2009; 250:1029-34.

30. Reddy HG, Shih T, Englesbe MJ, Shannon FL, Theurer PF, Herbert MA, et al Analyzing "failure to rescue": Is this an opportunity for outcome improvement in cardiac surgery? Ann Thorac Surg. 2013;95:1976-81.

31. Agency for Healthcare Research and Quality. Patient safety hospital quality metrics. Available at: http://www.qualityindicators.ahrq.gov. Accessed September $23,2014$.

32. Gonzalez AA, Dimick JB, Birkmeyer JD, Ghaferi AA. Understanding the volume-outcome effect in cardiovascular surgery: the role of failure to rescue. JAMA Surg. 2014;149:119-23.

33. Puvimanasinghe JP, Takkenberg JJ, Eijkemans MJ, Steyerberg EW van Herwerden LA, Grunkemeier GL, et al. Choice of a mechanical valve or a bioprosthesis for AVR: Does CABG matter? Eur J Cardio-Thorac Surg. 2003; 23:688-95.

34. Brinkman WT, Williams WH, Guyton RA, Jones EL, Craver JM. Valve replacement in patients on chronic renal dialysis: implications for valve prosthesis selection. Ann Thorac Surg. 2002;74:37-42.

Key Words: Aortic valve replacement, bioprosthetic valves, propensity score matching, comparative effectiveness, in-hospital mortality, national Inpatient sample 
TABLE E1. Balance assessment for propensity-matched cohort

\begin{tabular}{|c|c|c|c|c|c|c|}
\hline \multirow[b]{2}{*}{ Characteristic } & \multicolumn{3}{|c|}{$\begin{array}{l}\text { Unweighted, unmatched NIS data } \\
\text { (prematch c-statistic }=0.736)\end{array}$} & \multicolumn{3}{|c|}{$\begin{array}{c}\text { Propensity-matched data } \\
\text { (postmatch c-statistic }=0.517)\end{array}$} \\
\hline & $\begin{array}{c}\text { Bioprosthetic } \\
\text { AVR }(\mathrm{n}=\mathbf{8 2 , 3 1 2})\end{array}$ & $\begin{array}{c}\text { Mechanical } \\
\operatorname{AVR}(n=72,061)\end{array}$ & $\begin{array}{c}\text { Std. } \\
\text { Diff. }(\%)\end{array}$ & $\begin{array}{c}\text { Bioprosthetic } \\
\text { AVR }(\mathrm{n}=\mathbf{4 8 , 4 2 3})\end{array}$ & $\begin{array}{c}\text { Mechanical } \\
\operatorname{AVR}(n=48,423)\end{array}$ & $\begin{array}{c}\text { Std. } \\
\text { Diff. }(\%)\end{array}$ \\
\hline \multicolumn{7}{|l|}{ Procedure } \\
\hline CABG & $38,547(46.7)$ & 30,338 (41.9) & 9.7 & $21,941(45.3)$ & $22,026(45.5)$ & -0.4 \\
\hline Elective & $53,241(65.9)$ & $45,412(65.1)$ & 1.7 & $31,624(65.3)$ & $31,674(65.4)$ & -0.2 \\
\hline \multicolumn{7}{|l|}{ Patient } \\
\hline Age (mean $[y])$ & 71.6 & 64.9 & 52.1 & 68.7 & 68.6 & 0.6 \\
\hline Age (mean $[y])$ & & & 55.1 & & & 1.1 \\
\hline $18-39$ & $1779(2.2)$ & $3869(5.3)$ & & $1613(3.3)$ & $1675(3.5)$ & \\
\hline $40-49$ & $2531(3.1)$ & 6407 (8.9) & & $2320(4.8)$ & 2365 (4.9) & \\
\hline $50-54$ & $2505(3.0)$ & 5709 (7.9) & & $2274(4.7)$ & $2303(4.8)$ & \\
\hline $55-59$ & 4023 (4.9) & 7305 (10.1) & & $3516(7.3)$ & $3460(7.1)$ & \\
\hline $60-64$ & $6465(7.8)$ & $8178(11.3)$ & & $5008(10.3)$ & $4956(10.2)$ & \\
\hline $65-69$ & $10,671(12.9)$ & 9579 (13.2) & & $6992(14.4)$ & $6962(14.4)$ & \\
\hline $70-74$ & $15,108(18.3)$ & $10,382(14.3)$ & & 8421 (17.4) & 8477 (17.5) & \\
\hline $75-79$ & $18,263(22.1)$ & $10,714(14.8)$ & & 9134 (18.9) & 9138 (18.9) & \\
\hline $80-84$ & 6484 (7.9) & $2823(3.9)$ & & $2567(5.3)$ & $2548(5.3)$ & \\
\hline$\geq 85$ & $14,681(17.8)$ & $7398(10.2)$ & & 6578 (13.6) & 6539 (13.5) & \\
\hline Gender* & & & 3.7 & & & 0.2 \\
\hline Female & $31,070(37.7)$ & 25,947 (35.9) & & $18,021(37.2)$ & $17,969(37.1)$ & \\
\hline Race & & & 13.1 & & & 0.5 \\
\hline White & $57,320(69.5)$ & $45,894(63.4)$ & & $31,833(65.7)$ & $31,935(66.0)$ & \\
\hline Nonwhite & $8412(10.2)$ & 9413 (13.0) & & 5525 (11.4) & $5480(11.3)$ & \\
\hline Missing & $16,778(20.3)$ & 17,057 (23.6) & & 11,065 (22.9) & $11,008(22.7)$ & \\
\hline Year of procedure & & & 44.4 & & & 1.9 \\
\hline 1998 & $2703(3.3)$ & $5812(8.0)$ & & $2358(4.9)$ & $2282(4.7)$ & \\
\hline 1999 & 3504 (4.2) & $5677(7.8)$ & & $2608(5.4)$ & $2552(5.3)$ & \\
\hline 2000 & 3644 (4.4) & $6252(8.6)$ & & $3029(6.3)$ & $2953(6.1)$ & \\
\hline 2001 & $4466(5.4)$ & $5994(8.3)$ & & $3184(6.6)$ & $3206(6.6)$ & \\
\hline 2002 & $5098(6.2)$ & $5605(7.7)$ & & $3733(7.7)$ & $3784(7.8)$ & \\
\hline 2003 & $5174(6.3)$ & $5792(8.0)$ & & $3795(7.8)$ & $3865(8.0)$ & \\
\hline 2004 & $5390(6.5)$ & $5101(7.0)$ & & $3628(7.5)$ & $3681(7.6)$ & \\
\hline 2005 & $5668(6.9)$ & $4792(6.6)$ & & $3556(7.3)$ & $3526(7.3)$ & \\
\hline 2006 & $7319(8.9)$ & $4615(6.4)$ & & $3781(7.8)$ & $3783(7.8)$ & \\
\hline 2007 & $6541(7.9)$ & $4270(5.9)$ & & $3409(7.0)$ & $3451(7.1)$ & \\
\hline 2008 & $7511(9.1)$ & $4476(6.2)$ & & $3651(7.5)$ & $3748(7.7)$ & \\
\hline 2009 & $9123(11.1)$ & $4803(6.6)$ & & $3881(8.0)$ & $3940(8.1)$ & \\
\hline 2010 & $7385(9.0)$ & $4175(5.8)$ & & $3497(7.2)$ & $3467(7.2)$ & \\
\hline 2011 & $8984(10.9)$ & $5000(6.9)$ & & $4313(8.9)$ & $4185(8.6)$ & \\
\hline \multicolumn{7}{|l|}{ Diagnosis } \\
\hline Endocarditis & $2028(2.5)$ & $2027(2.8)$ & -2.2 & $1339(2.8)$ & $1342(2.8)$ & 0.0 \\
\hline Rheumatic valve disease & $10,714(13.0)$ & $7975(11.0)$ & 6.1 & $5660(11.7)$ & 5767 (11.9) & -0.7 \\
\hline Congenital aortic valve disease & $6538(7.9)$ & $6229(8.6)$ & -2.5 & $4034(8.3)$ & $4047(8.4)$ & -0.1 \\
\hline Thoracic aortic aneurysm & $5376(6.5)$ & $6236(8.6)$ & -8.0 & $3637(7.5)$ & $3598(7.4)$ & 0.3 \\
\hline \multicolumn{7}{|l|}{ Comorbidities } \\
\hline Chronic anticoagulation & $2595(3.1)$ & $2451(3.4)$ & -1.4 & $1543(3.2)$ & $1536(3.2)$ & 0.1 \\
\hline Coronary artery disease & $48,223(58.4)$ & $36,527(50.5)$ & 16.1 & $26,653(55.0)$ & $26,706(55.2)$ & -0.2 \\
\hline Congestive heart failure & $29,220(35.4)$ & $23,365(32.3)$ & 6.6 & $16,435(33.9)$ & $16,384(33.8)$ & 0.2 \\
\hline Hypertension & $42,946(52.0)$ & $35,106(48.5)$ & 7.1 & $24,587(50.8)$ & $24,579(50.8)$ & 0.0 \\
\hline Diabetes & $19,552(23.7)$ & $15,290(21.1)$ & 6.2 & $11,012(22.7)$ & $11,020(22.8)$ & 0.0 \\
\hline Chronic pulmonary disease & $16,159(19.6)$ & $13,237(18.3)$ & 3.3 & $9390(19.4)$ & $9265(19.1)$ & 0.7 \\
\hline Peripheral vascular disease & $14,700(17.8)$ & 14,209 (19.6) & -4.7 & 8989 (18.6) & $8941(18.5)$ & 0.3 \\
\hline Chronic renal insufficiency and/or failure & $6622(8.0)$ & $3048(4.2)$ & 16.0 & $2746(5.7)$ & $2728(5.6)$ & -0.5 \\
\hline
\end{tabular}




\begin{tabular}{|c|c|c|c|c|c|c|}
\hline \multirow[b]{2}{*}{ Characteristic } & \multicolumn{3}{|c|}{$\begin{array}{l}\text { Unweighted, unmatched NIS data } \\
\text { (prematch c-statistic }=\mathbf{0 . 7 3 6} \text { ) }\end{array}$} & \multicolumn{3}{|c|}{$\begin{array}{c}\text { Propensity-matched data } \\
(\text { postmatch c-statistic }=0.517)\end{array}$} \\
\hline & $\begin{array}{c}\text { Bioprosthetic } \\
\operatorname{AVR}(\mathbf{n}=\mathbf{8 2 , 3 1 2})\end{array}$ & $\begin{array}{c}\text { Mechanical } \\
\operatorname{AVR}(n=72,061)\end{array}$ & $\begin{array}{c}\text { Std. } \\
\text { Diff. }(\%)\end{array}$ & $\begin{array}{c}\text { Bioprosthetic } \\
\text { AVR }(n=48,423)\end{array}$ & $\begin{array}{c}\text { Mechanical } \\
\operatorname{AVR}(n=48,423)\end{array}$ & $\begin{array}{c}\text { Std. } \\
\text { Diff. }(\%)\end{array}$ \\
\hline Pulmonary circulatory disease & $7265(8.8)$ & $5792(8.0)$ & 2.9 & $4002(8.3)$ & $4071(8.4)$ & -0.3 \\
\hline Paralysis & $1062(1.3)$ & $844(1.2)$ & 1.1 & $581(1.2)$ & $595(1.2)$ & -0.5 \\
\hline Neurologic disorders & $2736(3.3)$ & $2052(2.8)$ & 2.8 & $1454(3.0)$ & $1499(3.1)$ & -0.3 \\
\hline Hypothyroidism & $7458(9.0)$ & $5210(7.2)$ & 6.7 & $3913(8.1)$ & $3946(8.1)$ & 0.2 \\
\hline Liver disease & $979(1.2)$ & $713(1.0)$ & 1.9 & $528(1.1)$ & $517(1.1)$ & -0.3 \\
\hline Arthritis & $1897(2.3)$ & 1357 (1.9) & 3.0 & $948(2.0)$ & $966(2.0)$ & 0.0 \\
\hline Coagulation disorders & $15,689(19.0)$ & $9725(13.4)$ & 15.2 & 7687 (15.9) & 7689 (15.9) & 0.4 \\
\hline Obesity & $7349(8.9)$ & $6576(9.1)$ & -0.6 & $4493(9.3)$ & $4436(9.2)$ & 0.3 \\
\hline Weight loss & $2148(2.6)$ & $1320(1.8)$ & 5.3 & $1074(2.2)$ & $1056(2.2)$ & -0.6 \\
\hline Electrolyte disorders & $17,711(21.5)$ & $12,543(17.3)$ & 10.5 & $9258(19.1)$ & $9365(19.3)$ & 0.0 \\
\hline Deficiency anemia & $11,970(14.5)$ & $8902(12.3)$ & 6.5 & $6482(13.4)$ & $6479(13.4)$ & 0.3 \\
\hline Psychiatric disorders & $1029(1.2)$ & $818(1.1)$ & 1.1 & $580(1.2)$ & $562(1.2)$ & -0.2 \\
\hline Depression & $3000(3.6)$ & $2484(3.4)$ & 1.1 & $1729(3.6)$ & $1751(3.6)$ & -0.5 \\
\hline \multicolumn{7}{|l|}{ History } \\
\hline Prior valve replacement & $746(0.9)$ & $1271(1.8)$ & -7.4 & $589(1.2)$ & $598(1.2)$ & -0.2 \\
\hline Prior CABG & $3840(4.7)$ & $2790(3.9)$ & 4.0 & $2090(4.3)$ & $2024(4.2)$ & 0.7 \\
\hline Prior PCI & $4690(5.7)$ & $2623(3.6)$ & 9.8 & $2062(4.3)$ & $2106(4.3)$ & -0.5 \\
\hline Insurance* & & & 41.2 & & & 0.8 \\
\hline Medicare & $60,151(72.9)$ & $38,719(53.5)$ & & $31,277(64.6)$ & $31,324(64.7)$ & \\
\hline Medicaid & $2041(2.5)$ & $3259(4.5)$ & & $1640(3.4)$ & $1676(3.5)$ & \\
\hline Commercial & $18,071(21.9)$ & $26,544(36.7)$ & & $13,812(28.5)$ & $13,783(28.5)$ & \\
\hline Other (uninsured) & $2173(2.6)$ & $3734(5.2)$ & & $1694(3.5)$ & $1640(3.4)$ & \\
\hline \multicolumn{7}{|l|}{ Hospital } \\
\hline Annual valve-procedure volume (mean) & 244.8 & 158.6 & 33.5 & 179.3 & 177.3 & 1.1 \\
\hline $\begin{array}{l}\text { Annual valve-procedure volume } \\
\text { (no. of procedures) }\end{array}$ & & & 38.5 & & & 0.4 \\
\hline $1-99$ & $23,730(28.8)$ & $32,800(45.3)$ & & $18,365(37.9)$ & $18,452(38.1)$ & \\
\hline $100-249$ & $33,223(40.3)$ & $26,305(36.4)$ & & $19,263(39.8)$ & $19,170(39.6)$ & \\
\hline$\geq 250$ & $25,557(31.0)$ & $13,259(18.3)$ & & $10,795(22.3)$ & $10,801(22.3)$ & \\
\hline \multicolumn{7}{|l|}{ Setting* } \\
\hline Teaching hospital & $55,839(67.8)$ & $46,666(64.8)$ & 6.5 & $31,943(66.0)$ & $31,831(65.7)$ & 0.5 \\
\hline Urban & $79,937(97.1)$ & $69,553(96.5)$ & 3.4 & $46,798(96.6)$ & $46,783(96.6)$ & 0.2 \\
\hline Region & & & 22.5 & & & 0.8 \\
\hline Northeast & $22,691(27.5)$ & $13,587(18.8)$ & & $10,659(22.0)$ & $10,796(22.3)$ & \\
\hline Midwest & $17,943(21.7)$ & $17,803(24.6)$ & & $11,512(23.8)$ & $11,374(23.5)$ & \\
\hline South & $24,728(30.0)$ & 26,485 (36.6) & & $17,129(35.4)$ & $17,124(35.4)$ & \\
\hline West & $17,148(20.8)$ & $14,489(20.0)$ & & $9123(18.8)$ & 9129 (18.9) & \\
\hline
\end{tabular}

Values are $\mathrm{n}(\%)$, unless otherwise indicated. All measures for comorbidities, except coronary artery disease and anticoagulation history, were created from definitions in the Elixhauser Comorbidity Index, using HCUP Comorbidity Software, version 3.7 (Agency for Healthcare Research and Quality, Rockville, Md.) NIS, National Inpatient Sample; $A V R$, aortic valve replacement; Std. Diff., standardized difference; $C A B G$, coronary artery bypass grafting; $P C I$, percutaneous coronary intervention. $*<3 \%$ missing. 
TABLE E2. In-hospital outcomes for mechanical versus bioprosthetic valve replacements performed in the period from 1998 to 2011 in patients without endocarditis who underwent isolated, first-time AVR

\begin{tabular}{|c|c|c|c|c|c|c|c|c|}
\hline \multirow[b]{2}{*}{ Outcome } & \multicolumn{4}{|c|}{ Weighted national estimates } & \multicolumn{4}{|c|}{ Propensity-matched cohort } \\
\hline & $\begin{array}{c}\text { Bioprosthetic } \\
\text { AVR } \\
(n=191,122)\end{array}$ & $\begin{array}{c}\text { Mechanical } \\
\text { AVR } \\
(n=176,394)\end{array}$ & $\begin{array}{l}\text { Odds ratio } \\
(95 \% \mathrm{CI})\end{array}$ & $\begin{array}{c}P \\
\text { value }\end{array}$ & $\begin{array}{c}\text { Bioprosthetic } \\
\text { AVR } \\
(\mathbf{n}=\mathbf{2 2 , 3 3 7 )}\end{array}$ & $\begin{array}{c}\text { Mechanical } \\
\text { AVR } \\
(\mathrm{n}=\mathbf{2 2 , 3 3 7 )}\end{array}$ & $\begin{array}{l}\text { Odds ratio } \\
(95 \% \mathrm{CI})\end{array}$ & $P$ value \\
\hline In-hospital mortality* & 6443 (3.4) & $6343(3.7)$ & $1.08(1-1.17)$ & .049 & $744(3.3)$ & $887(4.0)$ & $1.21(1.09-1.33)$ & $<.001$ \\
\hline $\begin{array}{r}\text { Composite outcome } \\
\text { (death or stroke) }\end{array}$ & $9172(4.9)$ & 8386 (4.9) & $1(0.94-1.07)$ & .956 & $1013(4.5)$ & $1188(5.3)$ & $1.18(1.09-1.29)$ & $<.001$ \\
\hline $\begin{array}{l}\text { Length of stay } \\
\qquad(\mathrm{d} ; \text { median }[\mathrm{IQR}])\end{array}$ & $7(5-11)$ & $7(5-11)$ & $\mathrm{n} / \mathrm{a}$ & $<.001 \dagger$ & $7(5-11)$ & $7(5-11)$ & $\mathrm{n} / \mathrm{a}$ & $<.001 \dagger$ \\
\hline \multicolumn{9}{|l|}{ Morbidity (complication) } \\
\hline Any & $80,822(42.8)$ & $63,799(37.0)$ & $0.79(0.76-0.81)$ & $<.001$ & $8918(39.9)$ & 8856 (39.6) & $0.99(0.95-1.03)$ & .547 \\
\hline Cardiovascular & $33,835(17.9)$ & $25,600(14.8)$ & $0.8(0.77-0.83)$ & $<.001$ & $3639(16.3)$ & $3571(16.0)$ & $0.98(0.93-1.03)$ & .379 \\
\hline Pulmonary & $44,824(23.7)$ & $35,781(20.8)$ & $0.84(0.81-0.87)$ & $<.001$ & $4911(22.0)$ & $5000(22.4)$ & $1.02(0.98-1.07)$ & .308 \\
\hline Infection & $14,305(7.6)$ & $9492(5.5)$ & $0.71(0.67-0.76)$ & $<.001$ & $1401(6.3)$ & $1469(6.6)$ & $1.05(0.98-1.14)$ & .188 \\
\hline Bleeding & $10,648(5.6)$ & $8705(5.0)$ & $0.89(0.83-0.95)$ & $<.001$ & $1235(5.5)$ & $1177(5.3)$ & $0.95(0.88-1.03)$ & .225 \\
\hline Thromboembolic & $33,835(17.9)$ & $25,600(14.8)$ & $0.8(0.77-0.83)$ & $<.001$ & $328(1.5)$ & $376(1.7)$ & $1.15(0.99-1.33)$ & .069 \\
\hline $\begin{array}{l}\text { Mortality in patients with } \\
\text { any complication }\end{array}$ & $5035 / 80,822(6.2)$ & 4605/63,799 (7.2) & $1.17(1.07-1.29)$ & $<.001$ & $570 / 8918(6.4)$ & $666 / 8856(7.5)$ & $1.17(0.97-1.4)$ & .107 \\
\hline \multicolumn{9}{|l|}{ Discharge status* } \\
\hline Routine & $71,858(38.1)$ & $90,973(52.9)$ & $1.82(1.77-1.88)$ & $<.001$ & 9941 (44.6) & $10,421(46.7)$ & $1.1(1.06-1.14)$ & $<.001$ \\
\hline
\end{tabular}

Values are $\mathrm{n}(\%)$, unless otherwise indicated. $A V R$, Aortic valve replacement; $C I$, confidence interval; $n / a$, not applicable; IQR, interquartile range. $*<0.01 \%$ missing. $\dagger$ Patients who received a mechanical valve had shorter length of stay in the national sample; those who received bioprosthetic valve had shorter length of stay in the propensity-matched cohort.

TABLE E3. In-hospital outcomes for mechanical versus bioprosthetic valve replacements performed in the period from 1998 to 2011 for patients in a propensity-matched cohort, with matching performed separately by facility

\begin{tabular}{|c|c|c|c|c|}
\hline Outcome & Bioprosthetic AVR $(n=23,248)$ & Mechanical AVR $(n=23,248)$ & Odds ratio $(95 \% \mathrm{CI})$ & $P$ value \\
\hline In-hospital mortality* & $993(4.3)$ & $1163(5.0)$ & $1.18(1.08-1.29)$ & $<.001$ \\
\hline Composite outcome (death or stroke) & $1401(6.0)$ & $1548(6.7)$ & $1.11(1.03-1.2)$ & .005 \\
\hline Length of stay (d; median [IQR]) & $8(5-12)$ & $8(6-12)$ & $\mathrm{n} / \mathrm{a}$ & $<.001$ \\
\hline \multicolumn{5}{|l|}{ Morbidity (complication) } \\
\hline Any & $10,167(43.7)$ & $9878(42.5)$ & $0.95(0.92-0.99)$ & .007 \\
\hline Cardiovascular & $4424(19.0)$ & $4077(17.5)$ & $0.9(0.86-0.95)$ & $<.001$ \\
\hline Pulmonary & $5447(23.4)$ & $5440(23.4)$ & $1(0.96-1.04)$ & .939 \\
\hline Infection & $1623(7.0)$ & $1672(7.2)$ & $1.03(0.96-1.11)$ & .376 \\
\hline Bleeding & $1470(6.3)$ & $1423(6.1)$ & $0.97(0.9-1.04)$ & .367 \\
\hline Thromboembolic & $399(1.7)$ & $416(1.8)$ & $1.04(0.91-1.2)$ & .548 \\
\hline Mortality in patients with any complication & $743 / 10,167(7.3)$ & $853 / 9878(8.7)$ & $1.19(1.07-1.32)$ & .001 \\
\hline \multicolumn{5}{|l|}{ Discharge status* } \\
\hline Routine & $10,010(43.1)$ & $9936(42.8)$ & $0.99(0.95-1.03)$ & .524 \\
\hline
\end{tabular}

Values are $\mathrm{n}(\%)$, unless otherwise indicated. $A V R$, Aortic valve replacement; $C I$, confidence interval; $I Q R$, interquartile range. $*<.01 \%$ missing. 